\title{
Influence of Loading Orientation and Knitted Versus Woven Transversal Connections in 3D Textile Reinforced Cement (TRC) Composites
}

\author{
Michael El Kadi *(D), Panagiotis Kapsalis, Danny Van Hemelrijck, Jan Wastiels ${ }^{(D)}$ and \\ Tine Tysmans 1 \\ Department Mechanics of Materials and Constructions, Vrije Universiteit Brussel (VUB), Pleinlaan 2, \\ 1050 Brussels, Belgium; Panagiotis.Kapsalis@vub.be (P.K.); Danny.Van.Hemelrijck@vub.be (D.V.H.); \\ jan.wastiels@vub.be (J.W.); tine.tysmans@vub.be (T.T.) \\ * Correspondence: michael.el.kadi@vub.be
}

Received: 2 June 2020; Accepted: 28 June 2020; Published: 29 June 2020

\begin{abstract}
As previous research has shown, the use of 3D textiles does not only facilitate the manufacturing process of Textile Reinforced Cement (TRC) composites but also influences the mechanical properties of the TRC. A fundamental understanding of the contribution of the transversal connections in the 3D textile to the loadbearing behavior of 3D TRCs is, however, still lacking in the literature. Therefore, this research experimentally investigates two different parameters of 3D TRCs; firstly, the 3D textile typology, namely knitted versus woven transversal connections, is investigated. Secondly, the influence of the stress direction with respect to the orientation of these connections (parallel or perpendicular) is studied. A clear influence of the orientation is witnessed for the woven 3D TRC system while no influence is observed for the knitted 3D TRC. Both woven and knitted 3D TRC systems show an increased post-cracking bending stiffness compared to an equivalent 2D system (with the same textiles but without transversal connections), yet the woven 3D TRC clearly outperforms the knitted 3D TRC.
\end{abstract}

Keywords: 3D textile fabrics; textile reinforced cement (TRC); transversal connections; mechanical characterization; tensile test; bending test; numerical simulation

\section{Introduction}

Textile Reinforced Cement (TRC) is a composite material combining a cementitious mortar (matrix) with textile fabric reinforcement. The matrix material warrants the structural integrity, while the textile reinforcement allows for a controlled and ductile tensile response of the composite [1-3]. The non-corroding nature of the textile reinforcement leads to a very low concrete cover thickness (a couple of $\mathrm{mm}$ ) and thus slender and lightweight construction elements. Challenging applications include ventilated façade panels [4], repair and strengthening realizations [5-10] and load-bearing applications such as shell structures [11-14], sandwich panels [15,16] and pedestrian bridges [17], demonstrating the material's proficiency towards lightweight, loadbearing applications.

The traditionally used planar textile fabrics in TRCs are associated with a hand-layup manufacturing process, which is adequate for strengthening applications $[8,18]$ but time-consuming and labor-intensive for precast TRC elements. Three-dimensional textile reinforcements allow for a TRC manufacturing process by pouring and moreover offer a mechanically superior alternative due to their superior toughness [19] and optimal fiber exploitation in flexural applications. Three-dimensional textiles comprise two (or more) planar textile layers, separated by means of fibrous transversal connections made of non-structural materials such as polyester. The transversal connections' purpose 
is to achieve a three-dimensional integrity of the textile. The transversal connections can be discretely knitted between the top and bottom textile layer, or woven and continuously intertwined between the top and bottom layer.

Previous studies have reported that the presence of the transversal connections leads to a superior flexural post-cracking stiffness of the TRC, without increasing the effective in-plane fiber volume fraction [20-22]. Amzaleg et al. [20] studied the influence of the properties, content and impregnation of the transversal connections on the mechanical properties of the TRC. They concluded that the transversal connections have a beneficial influence on the flexural properties of the TRC due to mechanical anchoring. El Kadi et al. compared the mechanical response of 3D TRCs with equivalent 2D TRCs, for four different layups in tension and bending, reporting a $25 \%$ post-cracking flexural stiffness increase of the 3D layups compared to their respective 2D alternatives [21]. Finally, Peled et al. [22] investigated the influence of loading the composite along the weft and the warp direction of the textile, concluding that the weft direction yielded a superior post-cracking stiffness and strength.

Research in the domain of 3D TRCs is still scarce, hampering an in-depth understanding of the occurring mechanical phenomena and their effect on the loadbearing behavior of 3D TRCs. In particular, on the subject of the loading direction, previous research has focused on the influence of loading TRC samples along the weft versus the warp direction of the in-plane textiles. An investigation of the influence of the loading direction with respect to the orientation in which the transversal connections are repeated is still lacking in the literature and is therefore the main research objective of this paper. An experimental campaign was performed on 3D textiles loaded parallel and perpendicular to the direction in which the transversal connections are repeated. Both a discretely knitted and a continuously woven 3D TRC configuration were considered in tension and bending. Additionally, the effect of the knitted and woven transversal connections was compared in both tension and bending to an equivalent 2D TRC system, with equal in-plane textiles but without transversal connections.

\section{Materials and Methods}

\subsection{Properties of Selected Textiles, Considered Layups and Matrix}

Three different TRC systems were compared in this study: a knitted 3D, a woven 3D and an equivalent 2D TRC system (Figure 1). The 2D textiles required for the equivalent 2D TRC layup were obtained by cutting through the knitted 3D textiles and therefore removing their transversal connections. The knitted (Figure 2) and the woven (Figure 3) 3D textiles differed at the following levels. Firstly, as can be seen in Table 1, the grid size of the knitted 3D textile was larger than the woven 3D textile. The 2400 tex yarns of the knitted textile (compared to 1200 tex for the woven textile), however, compensated for the larger grid size, leading to equal textile densities for both configurations and therefore the same unidirectional fiber volume fraction $(1.49 \%)$. Conversely, the knitted 3D textiles were styrene-butadiene coated. Previous studies have shown that coated textiles led to better mechanical anchorage within the matrix and therefore improved post-cracking stiffness and pull-out stress at failure [20,23-25]. Dvorkin et al. [23] concluded that coating multifilament carbon yarns improves mechanical behavior and bonding of the composite compared with non-coated carbon yarn composites. Donnini et al. [24] observed a promising enhancement of the bond between fabric and matrix, even with the use of low percentages of coating resin. Signorini et al. [25] highlighted the increased matrix-to-fabric strength due to epoxy coating in inorganic composites. Additionally, since the woven $3 \mathrm{D}$ textiles possessed continuously woven (polyester) transversal connections along the $y$-axis, these connections were intertwined with the in-plane yarns. The in-plane yarns along the y-axis were therefore not straightened but warped, while the weft yarns along the $x$-axis were straightened (Figure 3). A different behavior for this woven textile was therefore expected when loaded along the $x$ - and the $y$-axis, respectively. The knitted 3D textile did not possess this orientation-dependency from the in-plane yarns, since the connections were discretely knitted and did not impact the in-plane textiles' configuration. In addition, the discrete transversal connections of the knitted 3D TRC were not 
straightened over the thickness, but curved (Figure 2). The woven connections on the other hand were straightened at $45^{\circ}$ angles from the top to the bottom layer (Figure 3). The differences enumerated above and their possible influence on the mechanical properties of the TRC were taken into account in the discussion of the results.

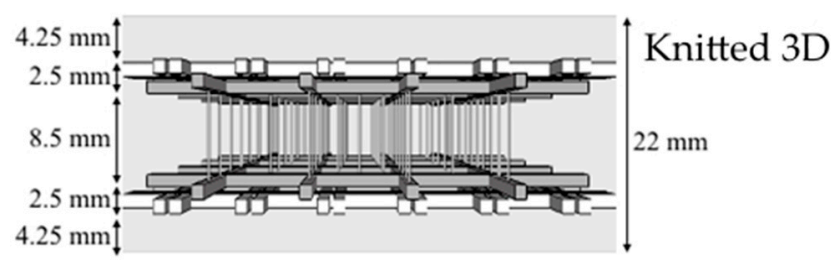

(a)

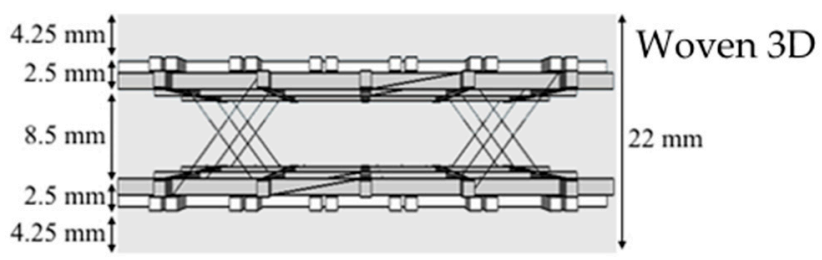

(b)

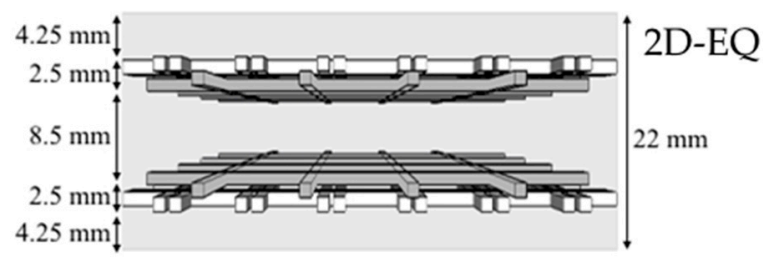

(c)

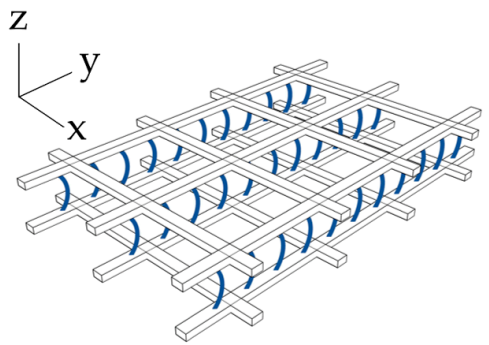

$\left(\mathbf{a}^{\prime}\right)$

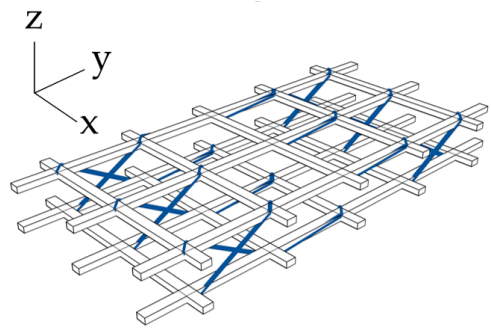

$\left(\mathbf{b}^{\prime}\right)$

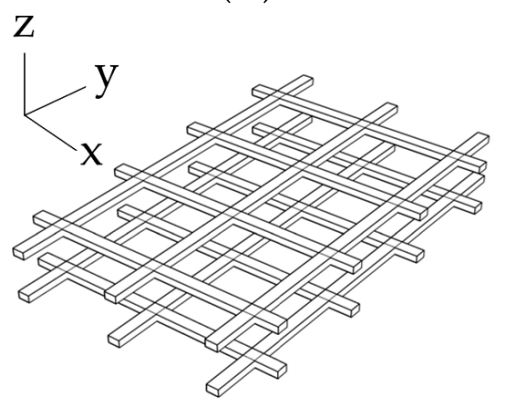

$\left(\mathbf{c}^{\prime}\right)$

Figure 1. Three considered Textile Reinforced Cement (TRC) layups, from top to bottom: knitted 3D TRC (a), woven 3D TRC (b) and equivalent 2D TRC (c). Left column represents the cross-sectional view of the layups, right column represents the schematics of the transversal connections with axis orientation $\left(\mathbf{a}^{\prime}, \mathbf{b}^{\prime}\right.$, and $\left.\mathbf{c}^{\prime}\right)$.

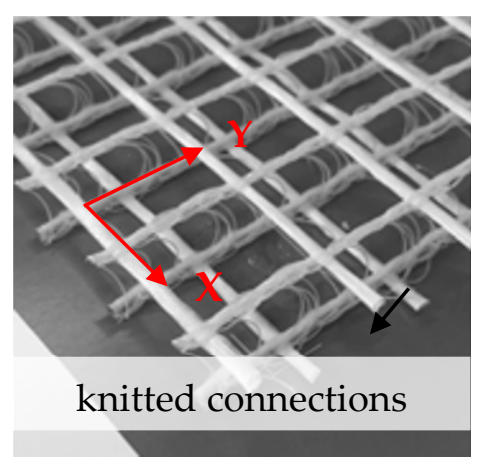

Figure 2. 3D, knitted textile. 


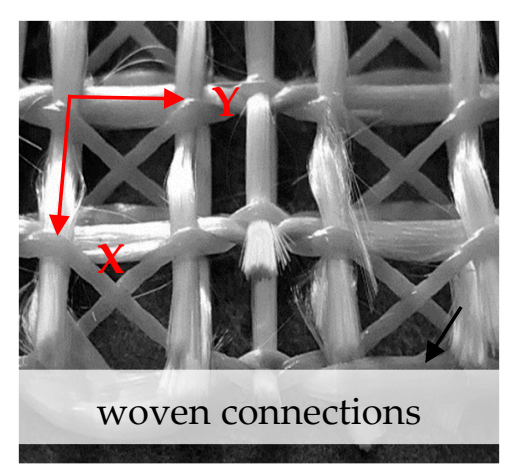

Figure 3. 3D, woven textile.

The 3D textiles were inserted in TRC specimens of $22 \mathrm{~mm}$ height and $4.25 \mathrm{~mm}$ concrete cover at both sides. The interdistance between the textile layers was $8.5 \mathrm{~mm}$ for all layups. For both considered 3D textiles, two outer 2D textile layers (Figure 4) were added: one on top and one at the bottom (see the white colored textiles in Figure 1a-c.

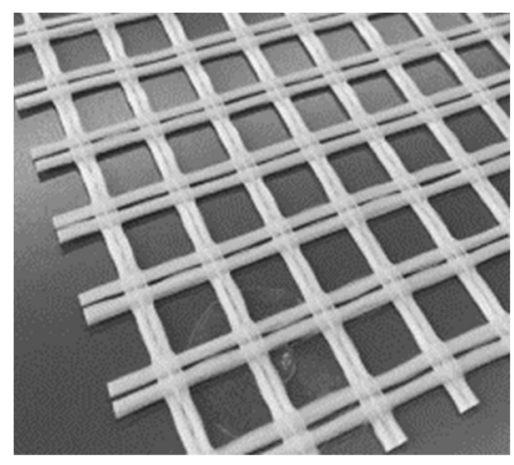

Figure 4. Planar, 2D glass textile.

These additional 2D textile layers were added to achieve a fiber volume fraction beyond the critical one. Without this addition, the unidirectional fiber volume fraction would have been too low $(0.56 \%)$ to warrant a post-cracking behavior of the TRC [26]. Therefore, two additional 2D TRC layers were manually knitted on top of the 3D textiles, resulting in a TRC with a unidirectional fiber volume fraction of $1.49 \%$.

The selected cementitious matrix was a commercially available grout which was chosen for its low viscosity in fresh state, in order to be pourable during the manufacturing process. Additionally, the maximum aggregate size of $1.6 \mathrm{~mm}$ allowed the 3D textiles to be fully interpenetrated. The main properties of the selected mortar [27] are summarized in Table 2.

Table 1. Properties of the constituting 3D and 2D textiles, based on [28-30].

\begin{tabular}{cccccccc}
\hline Textile & Material & $\begin{array}{c}\text { Grid Size } \\
(\mathbf{m m} \times \mathbf{m m})\end{array}$ & $\begin{array}{c}\text { Textile Density } \\
\mathbf{( g / \mathbf { m } ^ { 2 } )}\end{array}$ & $\begin{array}{c}\text { Equivalent } \\
\text { Thickness } \\
\mathbf{( m m )}\end{array}$ & $\begin{array}{c}\text { Yarn } \\
\text { Stiffness } \\
\mathbf{( G P a )}\end{array}$ & $\begin{array}{c}\text { Textile Max } \\
\text { Stress (MPa) }\end{array}$ & $\begin{array}{c}\text { Transversal } \\
\text { Connection }\end{array}$ \\
\hline Knitted 3D & AR-glass 2400 tex & $22.5 \times 22.5$ & 536 & 0.105 & 67 & 496 & knitted polyester \\
Woven 3D & AR-glass 1200 tex & $9.1 \times 9.1$ & 527 & 0.103 & 67 & 512 & woven polyester \\
2D & AR-glass 2400 tex & $17.5 \times 17.5$ & 568 & 0.223 & 67 & 526 & $/$ \\
\hline
\end{tabular}

Table 2. Properties of the cementitious matrix, based on [27].

\begin{tabular}{cccccc}
\hline $\begin{array}{c}\text { Aggregate Size. } \\
(\mathbf{m m})\end{array}$ & $\begin{array}{c}\text { Compressive } \\
\text { strength (28d) } \\
\mathbf{( M P a )}\end{array}$ & $\begin{array}{c}\text { Modulus of } \\
\text { Rupture (28d) } \\
\mathbf{( M P a )}\end{array}$ & $\begin{array}{c}\text { Density after } \\
\text { Mixing } \\
\left(\mathbf{k g} / \mathbf{m}^{3}\right)\end{array}$ & $\begin{array}{c}\text { Young's } \\
\text { Modulus } \\
(\mathbf{G P a})\end{array}$ & $\begin{array}{c}\text { Water/Mortar Ratio } \\
\mathbf{( - )}\end{array}$ \\
\hline $0-1.6$ & 70 & 12 & 2010 & 9 & 0.15 \\
\hline
\end{tabular}




\subsection{TRC Manufacturing Process}

All specimens were manufactured in $450 \times 500 \times 22 \mathrm{~mm}$ molds. The first manufacturing step was to apply an oil film at the bottom of the mold in order to facilitate the demolding process, as well as placing temporary distance holders (around the edges of the mold) to warrant the bottom concrete cover thickness. After mixing the matrix powder component with a water/mortar ratio of 0.15 , a bottom mortar layer was poured up to the level of the distance holders. The 3D textile was consequently placed on top of these distance holders, after which the rest of the mold was filled with mortar. The high flowability of the mortar allowed for complete textile penetration. A plastic film was placed over the mortar, after which the mold was sealed off and left to cure at room temperature for 28 days. Finally, the individual specimens were cut from the plates at dimensions of $450 \times 60 \times 22 \mathrm{~mm}$ (Figure 5). These specimen dimensions were employed for both the tensile and flexural experimental campaigns and are in accordance with the recommendations provided by RILEM TC 232-TDT [31].

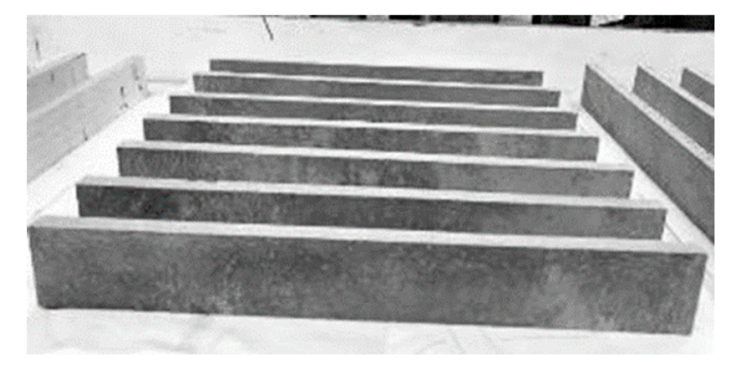

Figure 5. TRC samples after cutting.

For the equivalent 2D TRC layups, temporary distance holders of $8.5 \mathrm{~mm}$ were placed between the inner 2D textile layers within the mold to replicate the same geometrical spacing as in the 3D textiles. These distance holders were, however, placed along the cutting lines of the plate and therefore not present in the final tested specimens.

\subsection{Tensile and Flexural Experimental Test Setup}

The tensile test (Figure 6) was set up in accordance with [31]. The specimens were tightened using steel clamps by means of six tightening bolts at each end of the specimen. Rubber sheets were inserted between the clamps and the specimens in order to uniformly distribute the clamping stresses over the specimen's surface. The tensile anchorage length, defined as the distance from the clamp to the end of the specimen, was $125 \mathrm{~mm}$ at both sides of the tensile specimen. The tensile experimental campaign was performed on an Instron $5885 \mathrm{H}$ universal electromechanical test bench at a displacement controlled crosshead rate of $1 \mathrm{~mm} / \mathrm{min}$. A Digital Image Correlation (DIC) [32] system was employed to monitor the front of the specimen and obtain a full-field measurement of the displacements and strains over the $200 \mathrm{~mm}$ measurement length between the clamps. The loads were obtained directly from the Instron test bench.

The four-point bending experimental setup is schematized in Figure 7. The distance between the loading pins was $100 \mathrm{~mm}$, while the supports were placed $350 \mathrm{~mm}$ apart. The same Instron $5885 \mathrm{H}$ universal electromechanical test bench was used as in the tensile campaign, at a crosshead rate of $2 \mathrm{~mm} / \mathrm{min}$. Two DIC cameras were used to monitor the side of the specimens and obtain a full-field representation of the vertical displacement of the specimens. In bending, the textile anchorage length was defined as the distance from the loading pins to the free edge of the specimen. For this setup, the flexural anchorage length was $175 \mathrm{~mm}$ at both sides. 


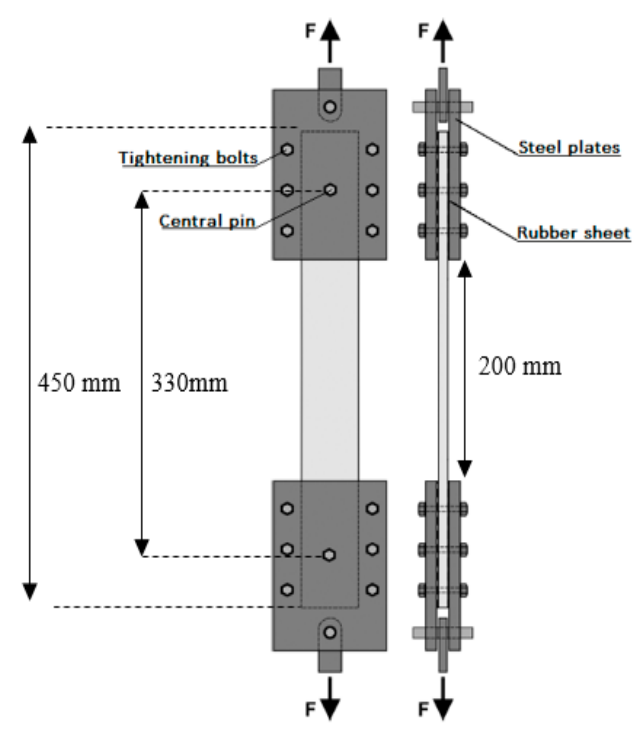

Figure 6. Tensile test setup

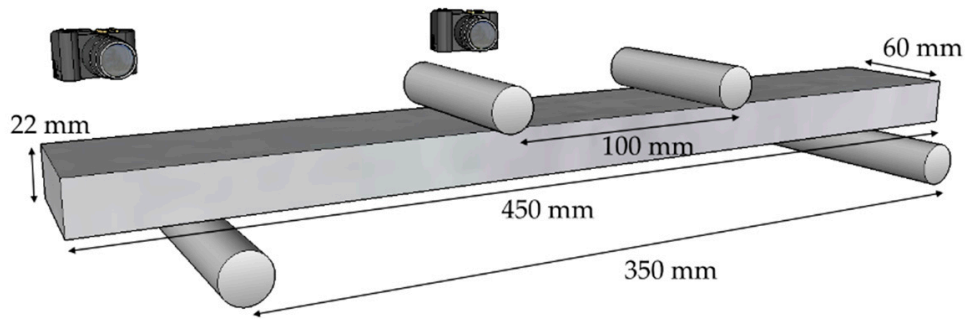

Figure 7. Four point bending test setup.

\section{Experimental Results and Discussion}

\subsection{Tensile Experimental Results}

In this section, the possible influence of the orientation of the transversal connections on the tensile mechanical response of the composite is discussed. Both the knitted 3D and woven 3D TRC configurations were compared for loading along their respective $\mathrm{x}$ - and $\mathrm{y}$-direction. The orientations are schematically shown in Figure 8a,b for the knitted 3D layup and in Figure 9a,b for the woven 3D layup. Additionally, a comparison was performed with an equivalent 2D TRC layup (Figure 1c). The equivalent 2D TRC had the same geometry and in-plane volume fraction as the $3 \mathrm{D}$ alternatives, with omission of the transversal connections.

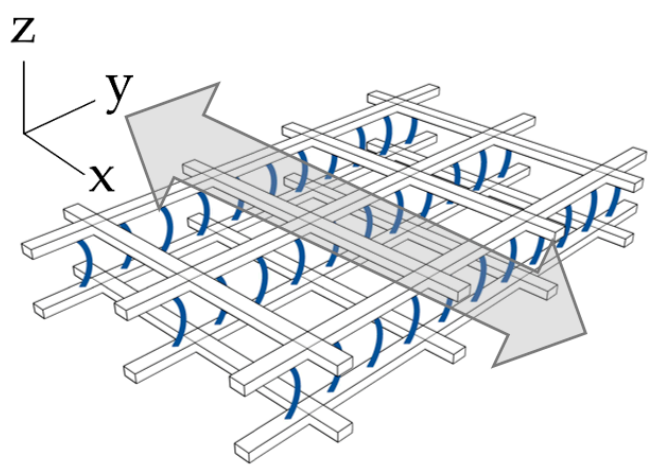

(a)

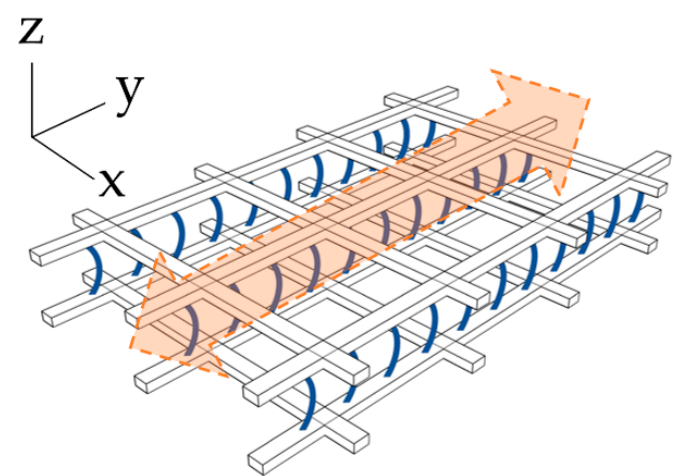

(b)

Figure 8. Schematic representation of loading in (a) x-direction, (b) y-direction for the knitted 3D TRC system. 


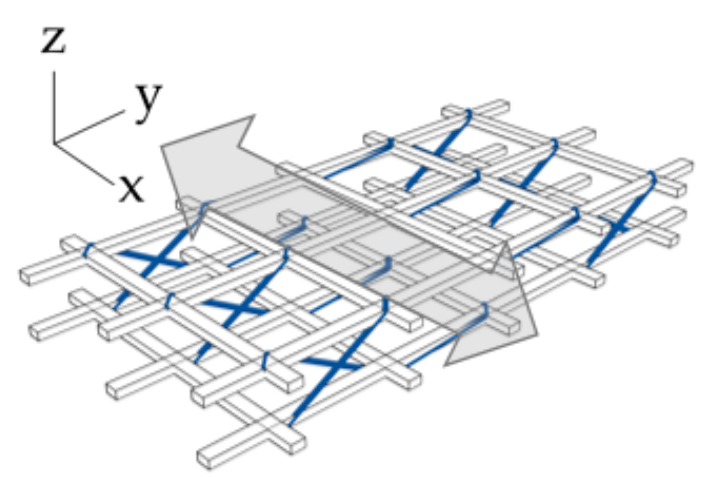

(a)

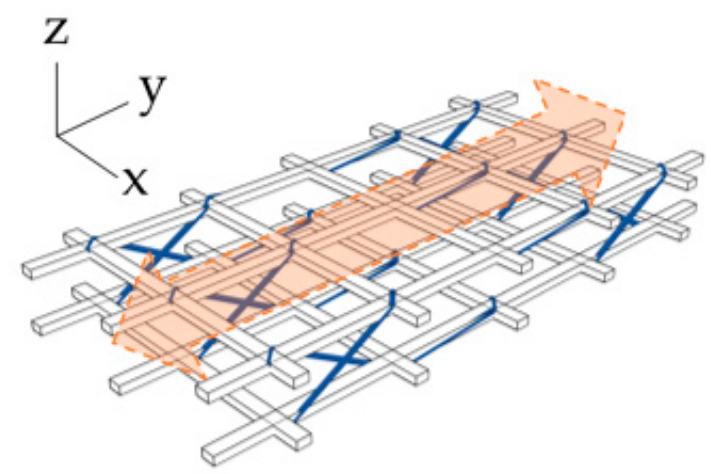

(b)

Figure 9. Schematic representation of loading in (a) x-direction, (b) y-direction for the woven 3D TRC system.

The macroscopic tensile behavior of a TRC composite shows three stages: a first stage without macrocracks, a second stage during which multiple cracking develops, and a third stage corresponding to crack opening. It can be assumed that this behavior follows a tri-linear pattern, corresponding to these three stages, with respective stiffnesses $E_{1}, E_{2}$ and $E_{3}$. In the following sections, the curves linearly connect the following anchor points: (i) point of zero loading $(0,0)$, (ii) stress and strain at first significant load drop due to crack formation $\left(\sigma_{\mathrm{c}}, \varepsilon_{\mathrm{c}}\right)$, (iii) stress and strain at the end of the multiple cracking (last significant load drop) $\left(\sigma_{\mathrm{mc}}, \varepsilon_{\mathrm{mc}}\right)$ and (iv) failure stress and strain $\left(\sigma_{\mathrm{f}}, \varepsilon_{\mathrm{f}}\right)$.

\subsubsection{Knitted 3D TRC}

Six specimens of the knitted 3D TRC were tested in tension along both the $\mathrm{x}$ - and the $\mathrm{y}$-direction of the 3D textile (Figure 8a,b). Figure 10 shows all of the experimental results in combination with a tri-linear average experimental curve obtained as described in the previous section. The experimental results of the knitted 3D TRC layup did not present a difference between both orientations; similar values of the average first and third stage stiffness $\left(E_{1}\right.$ and $\left.E_{3}\right)$, and the average stress and strain at matrix cracking $\left(\sigma_{\mathrm{c}}\right.$ and $\left.\varepsilon_{\mathrm{c}}\right)$, end of multiple cracking $\left(\sigma_{\mathrm{mc}}\right.$ and $\left.\varepsilon_{\mathrm{mc}}\right)$ and failure $\left(\sigma_{\mathrm{f}}\right.$ and $\left.\varepsilon_{\mathrm{f}}\right)$ (see Table 3$)$ were observed for both orientations. Therefore, the mechanical response in tension was considered as independent from the loading orientation for the knitted 3D TRC layup and the averaged curve was constructed using the experimental data from both orientations.

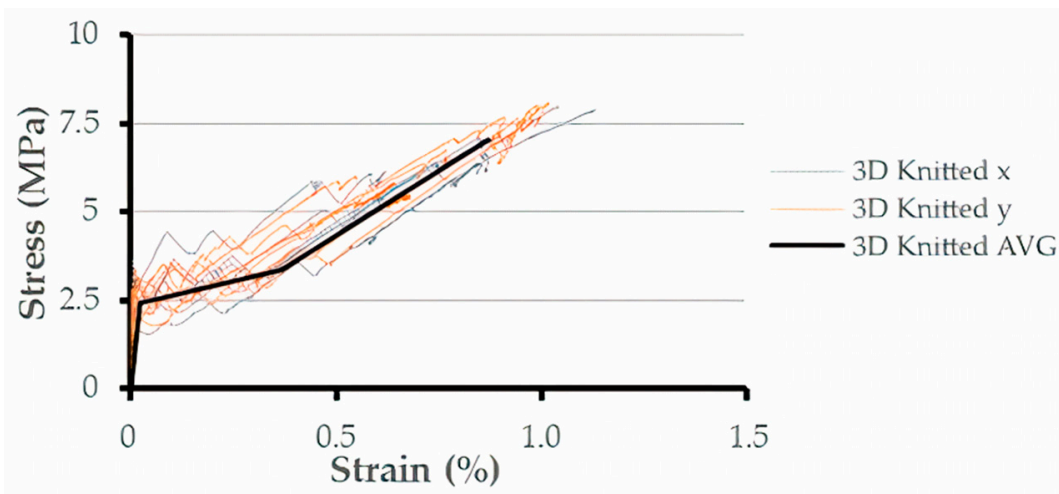

Along x:

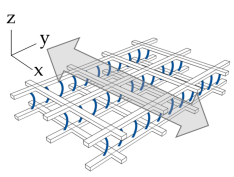

Figure 10. All tensile experimental curves in $\mathrm{x}$ - and $\mathrm{y}$-direction for the knitted 3D TRC layup, as well as averaged curve. 
Table 3. Averaged tensile experimental parameters for the knitted 3D TRC layup, as well as model predictions.

\begin{tabular}{|c|c|c|c|}
\hline \multicolumn{4}{|c|}{ Knitted 3D TRC, along $x, V_{f}=1.49 \%$} \\
\hline$\varepsilon_{0}(\%)$ & 0 & $\sigma_{0}(\mathrm{MPa})$ & 0 \\
\hline$\varepsilon_{\mathrm{c}}(\%)$ & 0.022 & $\sigma_{\mathrm{c}}(\mathrm{MPa})$ & 2.47 \\
\hline$\varepsilon_{\mathrm{mc}}(\%)$ & 0.365 & $\sigma_{\mathrm{mc}}(\mathrm{MPa})$ & 3.40 \\
\hline$\varepsilon_{\mathrm{f}}(\%)$ & 0.880 & $\sigma_{\mathrm{f}}(\mathrm{MPa})$ & 7.03 \\
\hline \multicolumn{2}{|c|}{$\mathrm{E}_{1}(\mathrm{MPa})$} & \multicolumn{2}{|c|}{$11,027 \pm 541$} \\
\hline \multicolumn{2}{|c|}{$\mathrm{E}_{2}(\mathrm{MPa})$} & \multicolumn{2}{|c|}{$271 \pm 73$} \\
\hline \multicolumn{2}{|c|}{$\mathrm{E}_{3}(\mathrm{MPa})$} & \multicolumn{2}{|c|}{$710 \pm 45$} \\
\hline \multicolumn{4}{|c|}{ Knitted 3D TRC, along $\mathrm{y}, \mathrm{V}_{\mathrm{f}}=1.49 \%$} \\
\hline$\varepsilon_{0}(\%)$ & 0 & $\sigma_{0}(\mathrm{MPa})$ & 0 \\
\hline$\varepsilon_{\mathrm{C}}(\%)$ & 0.022 & $\sigma_{\mathrm{c}}(\mathrm{MPa})$ & 2.41 \\
\hline$\varepsilon_{\mathrm{mc}}(\%)$ & 0.369 & $\sigma_{\mathrm{mc}}(\mathrm{MPa})$ & 3.36 \\
\hline$\varepsilon_{\mathrm{f}}(\%)$ & 0.840 & $\sigma_{\mathrm{f}}(\mathrm{MPa})$ & 7.01 \\
\hline \multicolumn{2}{|c|}{$\mathrm{E}_{1}(\mathrm{MPa})$} & \multicolumn{2}{|c|}{$10,919 \pm 532$} \\
\hline \multicolumn{2}{|c|}{$\mathrm{E}_{2}(\mathrm{MPa})$} & \multicolumn{2}{|c|}{$275 \pm 77$} \\
\hline \multicolumn{2}{|c|}{$\mathrm{E}_{3}(\mathrm{MPa})$} & \multicolumn{2}{|c|}{$738 \pm 48$} \\
\hline \multicolumn{4}{|c|}{ Knitted 3D TRC, all, Vf $=1.49 \%$} \\
\hline$\varepsilon_{0}(\%)$ & 0 & $\sigma_{0}(\mathrm{MPa})$ & 0 \\
\hline$\varepsilon_{\mathrm{c}}(\%)$ & 0.022 & $\sigma_{\mathrm{c}}(\mathrm{MPa})$ & 2.44 \\
\hline$\varepsilon_{\mathrm{mc}}(\%)$ & 0.367 & $\sigma_{\mathrm{mc}}(\mathrm{MPa})$ & 3.38 \\
\hline$\varepsilon_{\mathrm{f}}(\%)$ & 0.860 & $\sigma_{\mathrm{f}}(\mathrm{MPa})$ & 7.02 \\
\hline \multicolumn{2}{|c|}{$\mathrm{E}_{1}(\mathrm{MPa})$} & \multicolumn{2}{|c|}{$10,973 \pm 534$} \\
\hline \multicolumn{2}{|c|}{$\mathrm{E}_{2}(\mathrm{MPa})$} & \multicolumn{2}{|c|}{$273 \pm 74$} \\
\hline \multicolumn{2}{|c|}{$\mathrm{E}_{3}(\mathrm{MPa})$} & \multicolumn{2}{|c|}{$724 \pm 46$} \\
\hline
\end{tabular}

The observed experimental scatter on the experimental curves (Figure 10) was attributed to the relatively low amount of unidirectional fiber reinforcement $\left(\mathrm{V}_{\mathrm{f}}=1.49 \%\right)$ inherent to the open $3 \mathrm{D}$ textile architecture. Consequently, individual cracks led to noticeable load drops and a subsequent stochastic scatter between the individual specimens. In opposition to the high scatter on the multiple cracking stage, the uncracked and post-cracking stiffness showed low standard deviations values (Table 3). The observed specimen failure was fiber pull-out for both orientations at an average pull-out stress of 7.02 MPa.

Figure 11 compares the averaged curves of the knitted 3D with the equivalent 2D layup. The global macroscopic behavior of the equivalent 2D TRC layup in tension was similar to the knitted 3D TRC layup, as concluded in [21]. At the level of the post-cracking stiffness, no influence was observed from the layups containing transversal connections, as can be seen in Table 4 . This means that the presence of transversal connections did not activate any further anchorage of the in-plane textiles under tensile loading conditions when compared to a layup without transversal connections. 


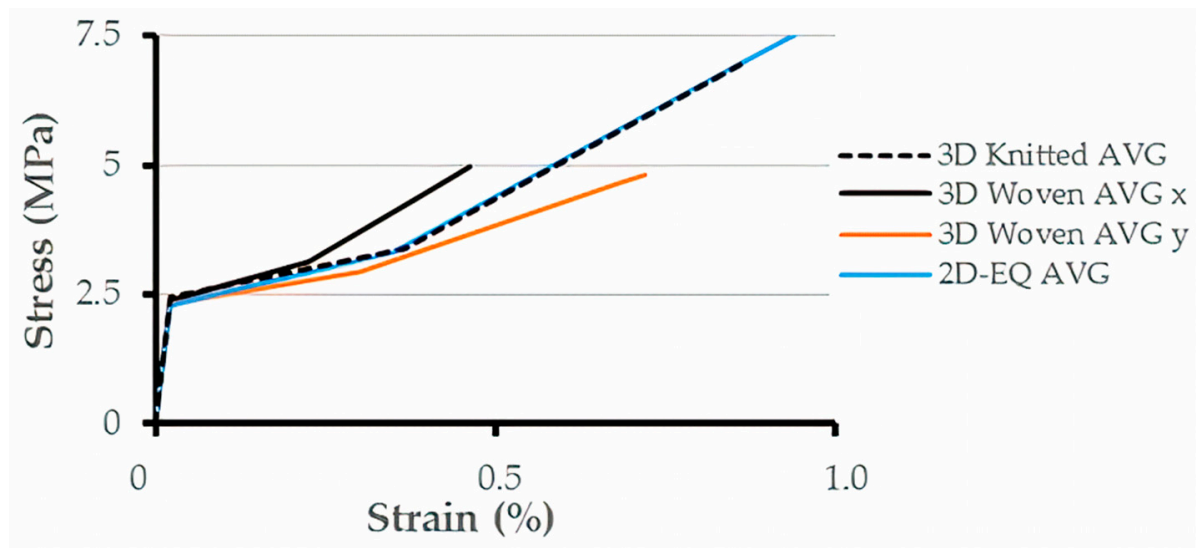

Figure 11. Tensile comparison of averaged curves of all layups.

Table 4. Averaged stiffness in three stages in tension for all layups.

\begin{tabular}{ccccc}
\hline & Knitted 3D AVG & Woven 3D AVG $\mathbf{x}$ & Woven 3D AVG y & 2D-EQ AVG \\
\hline $\mathrm{E}_{1}(\mathrm{MPa})$ & 10,973 & 10,903 & 10,957 & 10,736 \\
$\mathrm{E}_{2}(\mathrm{MPa})$ & 273 & 365 & 229 & 318 \\
$\mathrm{E}_{3}(\mathrm{MPa})$ & 724 & 761 & 446 & 710 \\
\hline
\end{tabular}

\subsubsection{Woven 3D TRC}

Six specimens of the woven 3D TRC were tested in tension along the $\mathrm{x}$ - and $\mathrm{y}$-direction. Figure 12 compares the experimental curves for both orientations and provides their respective averaged curves.

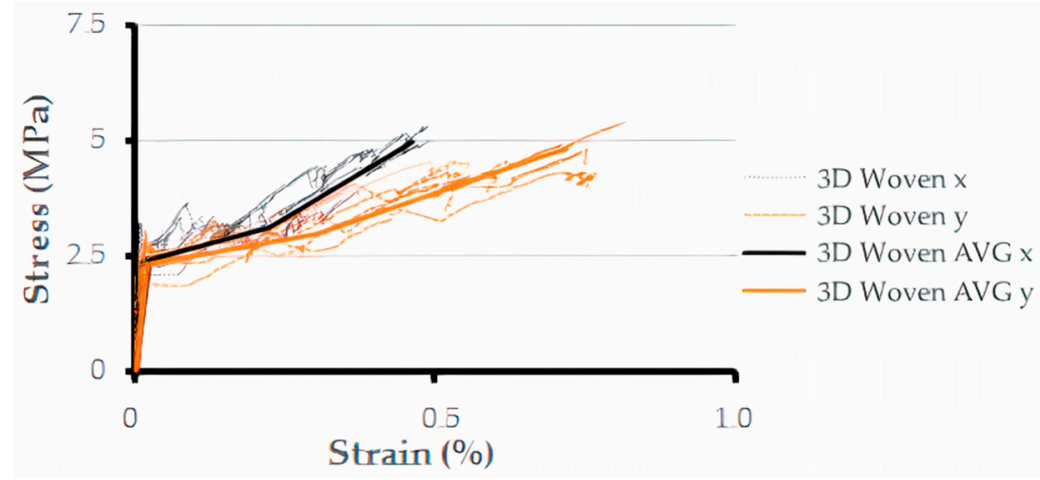

Along x:

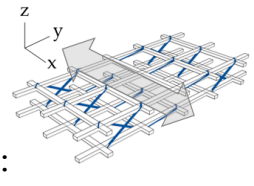

Along y:

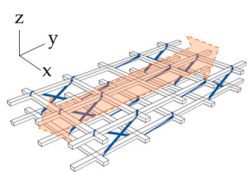

Figure 12. All tensile experimental curves in $x$ - and $y$-direction for the woven 3D TRC layup, as well as averaged curves.

Table 5 summarizes all of the tensile parameters in both orientations for the woven 3D layup. In the first stage, both orientations showed a similar uncracked stiffness $E_{1}$ and matrix cracking stress. This was expected since the first stage is dominated by the properties of the matrix. In the third stage however, a clear difference in post-cracking stiffness was observed: $761 \mathrm{MPa}$ in the x-direction compared to $446 \mathrm{MPa}$ in the y-direction. This was expected since for the woven 3D textiles, the weft yarns along the $x$-axis were straightened, while the warp yarns along the $y$-axis were not. Both orientations failed by means of fiber pull-out at similar stress values (respectively 4.96 MPa and $4.82 \mathrm{MPa}$ along $\mathrm{x}$ and $\mathrm{y}$ ). The larger failure strain in the $\mathrm{y}$-direction, without an increase in failure stress, further indicated that the fibers were originally not straightened in this direction. 
Table 5. Averaged tensile experimental parameters for the woven 3D TRC layup.

\begin{tabular}{|c|c|c|c|c|c|c|c|}
\hline \multicolumn{4}{|c|}{ Woven 3D TRC, Along $x, V_{f}=1.49 \%$} & \multicolumn{4}{|c|}{ Woven 3D TRC, Along $\mathrm{y}, \mathrm{V}_{\mathrm{f}}=1.49 \%$} \\
\hline$\varepsilon_{0}(\%)$ & 0 & $\sigma_{0}(\mathrm{MPa})$ & 0 & $\varepsilon_{0}(\%)$ & 0 & $\sigma_{0}(\mathrm{MPa})$ & 0 \\
\hline$\varepsilon_{\mathrm{c}}(\%)$ & 0.022 & $\sigma_{\mathrm{c}}(\mathrm{MPa})$ & 2.40 & $\varepsilon_{\mathrm{c}}(\%)$ & 0.021 & $\sigma_{\mathrm{c}}(\mathrm{MPa})$ & 2.31 \\
\hline$\varepsilon_{\mathrm{mc}}(\%)$ & 0.225 & $\begin{array}{c}\sigma_{\mathrm{mc}} \\
(\mathrm{MPa})\end{array}$ & 3.14 & $\varepsilon_{\mathrm{mc}}(\%)$ & 0.301 & $\begin{array}{c}\sigma_{\mathrm{mc}} \\
(\mathrm{MPa})\end{array}$ & 2.95 \\
\hline$\varepsilon_{\mathrm{f}}(\%)$ & 0.464 & $\sigma_{\mathrm{f}}(\mathrm{MPa})$ & 4.96 & $\varepsilon_{\mathrm{f}}(\%)$ & 0.719 & $\sigma_{\mathrm{f}}(\mathrm{MPa})$ & 4.82 \\
\hline \multicolumn{2}{|c|}{$\mathrm{E}_{1}(\mathrm{MPa})$} & \multicolumn{2}{|c|}{$10,903 \pm 705$} & \multicolumn{2}{|c|}{$\mathrm{E}_{1}(\mathrm{MPa})$} & \multicolumn{2}{|c|}{$10,957 \pm 812$} \\
\hline \multicolumn{2}{|c|}{$\mathrm{E}_{2}(\mathrm{MPa})$} & \multicolumn{2}{|c|}{$365 \pm 64$} & \multicolumn{2}{|c|}{$\mathrm{E}_{2}(\mathrm{MPa})$} & \multicolumn{2}{|c|}{$229 \pm 38$} \\
\hline \multicolumn{2}{|c|}{$\mathrm{E}_{3}(\mathrm{MPa})$} & \multicolumn{2}{|c|}{$761 \pm 44$} & \multicolumn{2}{|c|}{$\mathrm{E}_{3}(\mathrm{MPa})$} & \multicolumn{2}{|c|}{$446 \pm 35$} \\
\hline
\end{tabular}

Comparing the knitted 3D and woven 3D layups (Tables 3 and 5), the following conclusions were drawn. Firstly, as expected, the first stage stiffness $E_{1}$ and matrix cracking stress $\sigma_{\mathrm{c}}$ were similar for both layups. Secondly, the post-cracking stiffness along the x-direction of the woven 3D layup was also similar to the results in both directions of the knitted 3D layup. This is in accordance with [21], which concluded that no contribution could be expected from knitted transversal connections on the tensile mechanical behavior of TRC. This was also confirmed in Figure 11 and Table 4, which showed a similar stiffness for the woven 3D TRC and the equivalent 2D layup.

Additionally, the lower pull-out stress of the woven 3D compared to the knitted 3D (4.96 MPa and $4.82 \mathrm{MPa}$ compared to $7.02 \mathrm{MPa}$ ) can be attributed to the lack of SBR (styrene-butadiene) coating of the woven 3D layup, as concluded in [20,23-25].

\subsection{Flexural Experimental Results}

This section assesses the influence of the orientation of the transversal connections on the flexural response of TRC composites. The same two orientations were considered as in tension for the knitted 3D and woven 3D layup (given respectively in Figures 8 and 9).

Again, average curves were constructed from the obtained experimental results discussed in the following sections. The curves linearly connect the following anchor points: (i) point of zero loading $(0,0)$, (ii) force and displacement at first significant load drop $\left(\mathrm{F}_{\mathrm{c}}, \mathrm{d}_{\mathrm{c}}\right)$, (iii) force and displacement at the end of the multiple cracking (last significant load drop) $\left(\mathrm{F}_{\mathrm{mc}}, \mathrm{d}_{\mathrm{mc}}\right)$ and (iv) stress and strain $\left(\mathrm{F}_{\mathrm{f}}, \mathrm{d}_{\mathrm{f}}\right)$ at initiation of pull-out. A last linear branch was added in the flexural curves to account for the large pull-out strains observed in bending (compared to tension).

\subsubsection{Knitted 3D TRC}

In bending, four specimens were tested for each orientation of the knitted 3D TRC. The experimental force-displacement curves for both orientations are given in Figure 13. Similar to the tensile results, no influence of the orientation on the mechanical response was observed for this layup, while the observed failure was by means of fiber pull-out. Table 6 summarizes all averaged flexural experimental parameters for this layup, which were taken as the average of both orientations. The Ks in the table represent the stiffness of the load-displacement curves.

Figure 14 compares the averaged flexural experimental curves of the knitted 3D TRC with the equivalent 2D TRC (properties given in Table 7, according to [21]). Table 8 summarizes the flexural stiffness in the three stages for the different layups. 


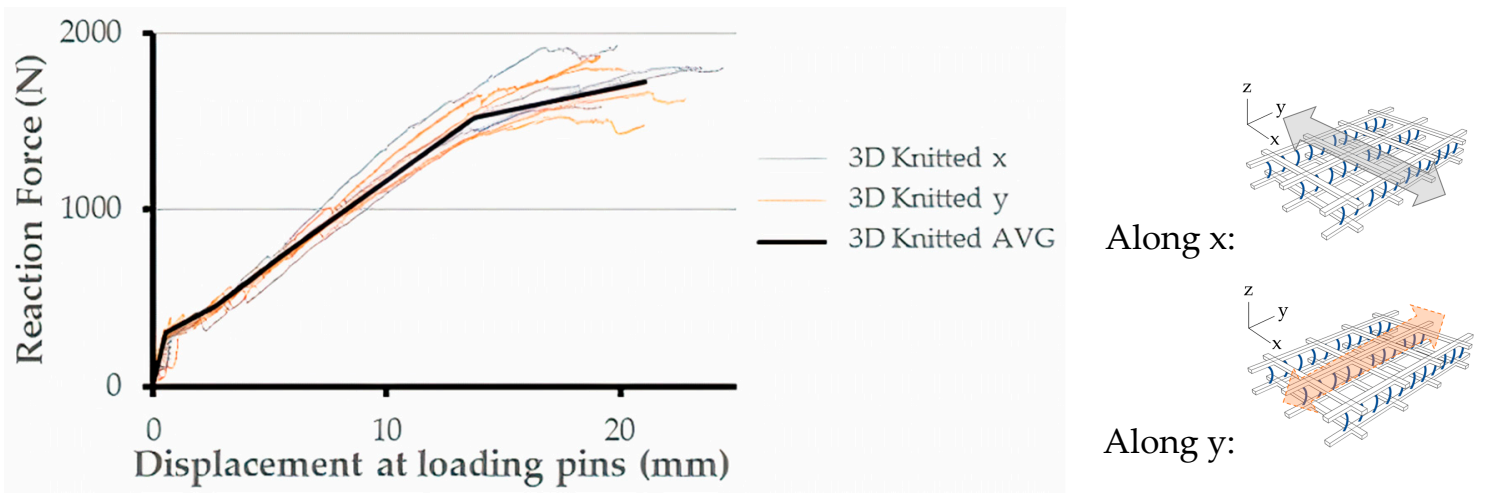

Figure 13. All flexural experimental curves in $x$ - and y-direction for the knitted 3D TRC layup, as well as averaged curve.

Table 6. Averaged flexural experimental parameters for the knitted 3D TRC layup.

\begin{tabular}{cccc}
\hline \multicolumn{4}{c}{ Knitted 3D TRC, All Specimens, Vf $=\mathbf{1 . 4 9 \%}$} \\
\hline $\mathrm{d}_{0}(\mathrm{~mm})$ & 0 & $\mathrm{~F}_{0}(\mathrm{~N})$ & 0 \\
$\mathrm{~d}_{\mathrm{c}}(\mathrm{mm})$ & 0.562 & $\mathrm{~F}_{\mathrm{c}}(\mathrm{N})$ & 310 \\
$\mathrm{~d}_{\mathrm{mc}}(\mathrm{mm})$ & 2.711 & $\mathrm{~F}_{\mathrm{mc}}(\mathrm{N})$ & 460 \\
$\mathrm{~d}_{\mathrm{f}}(\mathrm{mm})$ & 14.045 & $\mathrm{~F}_{\mathrm{f}}(\mathrm{N})$ & 1503 \\
$\mathrm{~K}_{1}(\mathrm{~N} / \mathrm{mm})$ & $551 \pm 48$ \\
$\mathrm{~K}_{2}(\mathrm{~N} / \mathrm{mm})$ & $70 \pm 12$ \\
$\mathrm{~K}_{3}(\mathrm{~N} / \mathrm{mm})$ & \multicolumn{2}{c}{$92 \pm 7$} \\
\hline
\end{tabular}

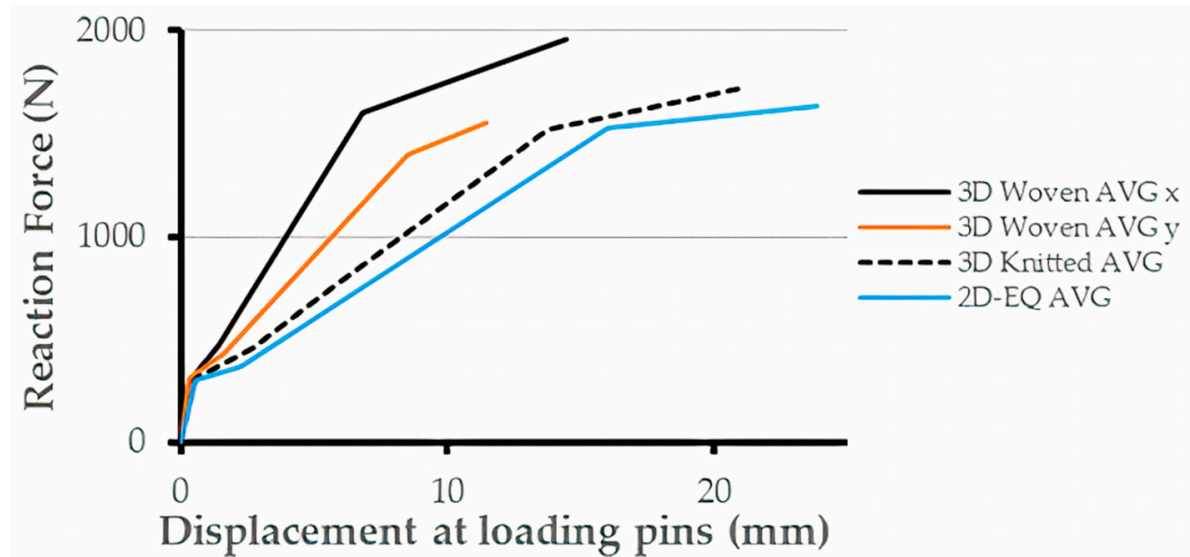

Figure 14. Flexural comparison of averaged curves of all layups.

Table 7. Averaged flexural experimental parameters for the equivalent 2D TRC layup.

\begin{tabular}{|c|c|c|c|}
\hline \multicolumn{4}{|c|}{ Equivalent 2D TRC, All Specimens, Vf $=1.49 \%$} \\
\hline $\mathrm{d}_{0}(\mathrm{~mm})$ & 0 & $\mathrm{~F}_{0}(\mathrm{~N})$ & 0 \\
\hline $\mathrm{d}_{\mathrm{c}}(\mathrm{mm})$ & 0.555 & $\mathrm{~F}_{\mathrm{C}}(\mathrm{N})$ & 306 \\
\hline $\mathrm{d}_{\mathrm{mc}}(\mathrm{mm})$ & 1.848 & $\mathrm{~F}_{\mathrm{mc}}(\mathrm{N})$ & 395 \\
\hline $\mathrm{d}_{\mathrm{f}}(\mathrm{mm})$ & 16.503 & $\mathrm{~F}_{\mathrm{f}}(\mathrm{N})$ & 1456 \\
\hline \multicolumn{2}{|c|}{$\mathrm{K}_{1}(\mathrm{~N} / \mathrm{mm})$} & \multicolumn{2}{|c|}{$552 \pm 42$} \\
\hline \multicolumn{2}{|c|}{$\mathrm{K}_{2}(\mathrm{~N} / \mathrm{mm})$} & \multicolumn{2}{|c|}{$68 \pm 19$} \\
\hline \multicolumn{2}{|c|}{$\mathrm{K}_{3}(\mathrm{~N} / \mathrm{mm})$} & \multicolumn{2}{|c|}{$72 \pm 3$} \\
\hline
\end{tabular}


Table 8. Averaged stiffness in three stages in bending for all layups.

\begin{tabular}{lcccc}
\hline & Knitted 3D AVG & Woven 3D AVG & Woven 3D AVG & \multirow{2}{*}{ 2D-EQ AVG } \\
\hline $\mathrm{K}_{1}(\mathrm{~N} / \mathrm{mm})$ & 551 & 536 & $\mathbf{y}$ & \\
$\mathrm{K}_{2}(\mathrm{~N} / \mathrm{mm})$ & 70 & 166 & 558 & 552 \\
$\mathrm{~K}_{3}(\mathrm{~N} / \mathrm{mm})$ & 92 & 218 & 103 & 68 \\
\hline
\end{tabular}

Contrary to the tensile behavior, the post-cracking stiffness of the 3D TRC layups showed a clear improvement compared to the equivalent 2D layup.

The knitted 3D TRC layup showed a clearly higher post-cracking stiffness compared to the reference equivalent 2D TRC ( $92 \mathrm{~N} / \mathrm{mm}$ compared to $72 \mathrm{~N} / \mathrm{mm}$, Table 8$)$, while having the same in-plane fiber volume fraction. These results highlighted the increased flexural anchorage and therefore higher fiber efficiency provided by the transversal connections in the 3D TRC layups.

\subsubsection{Woven $3 \mathrm{D}$ TRC}

Three specimens were tested in bending for each orientation of the woven 3D TRC layup. Figure 15 summarizes the experimental curves along both orientations. Similarly to tension, the uncracked stage yielded comparable results for both orientations, and the post-cracking stage showed a preference in the $x$-direction because the in-plane weft yarns in the $x$-direction were straightened while the warped yarns in the y-direction were not. All the experimental flexural parameters are given in Table 9.
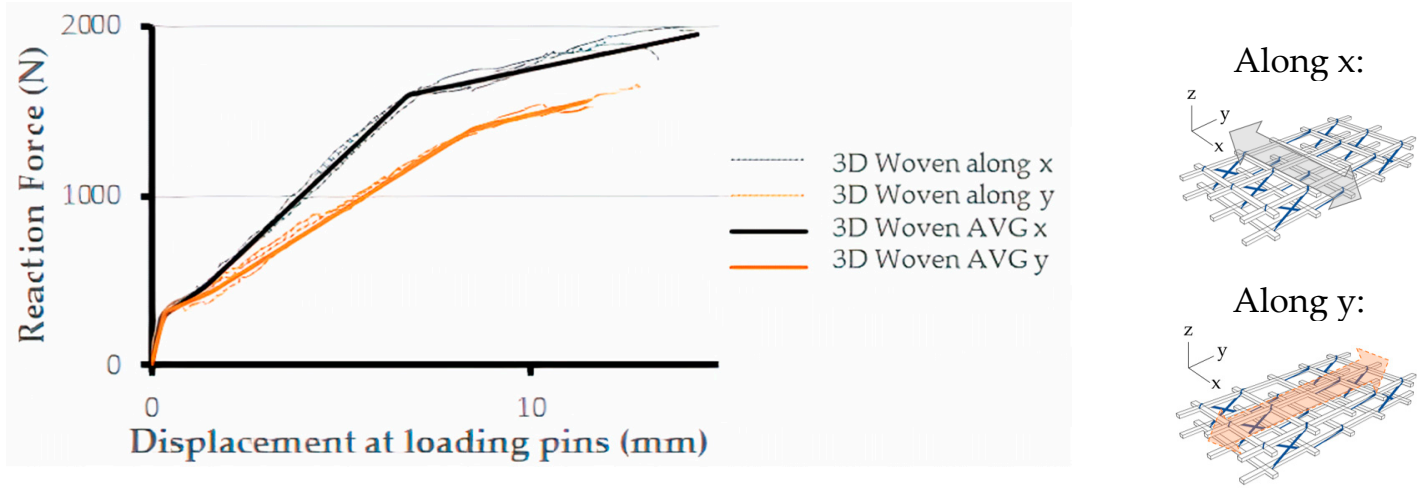

Figure 15. All flexural experimental curves in $x$ - and $y$-direction for the woven 3D TRC layup, as well as averaged curves.

Table 9. Averaged flexural experimental parameters for the woven 3D TRC layup.

\begin{tabular}{cccccccc}
\hline \multicolumn{3}{c}{ Woven 3D TRC, Along $\mathbf{x}, \mathbf{V}_{\mathbf{f}}=\mathbf{1 . 4 9} \%$} & \multicolumn{3}{c}{ Woven 3D TRC, Along $\mathbf{y}, \mathbf{V}_{\mathbf{f}}=\mathbf{1 . 4 9 \%}$} \\
\hline $\mathrm{d}_{0}(\mathrm{~mm})$ & 0 & $\mathrm{~F}_{0}(\mathrm{~N})$ & 0 & $\mathrm{~d}_{0}(\mathrm{~mm})$ & 0 & $\mathrm{~F}_{0}(\mathrm{~N})$ & 0 \\
$\mathrm{~d}_{\mathrm{c}}(\mathrm{mm})$ & 0.542 & $\mathrm{~F}_{\mathrm{c}}(\mathrm{N})$ & 290 & $\mathrm{~d}_{\mathrm{c}}(\mathrm{mm})$ & 0.561 & $\mathrm{~F}_{\mathrm{c}}(\mathrm{N})$ & 313 \\
$\mathrm{~d}_{\mathrm{mc}}(\mathrm{mm})$ & 1.661 & $\mathrm{~F}_{\mathrm{mc}}(\mathrm{N})$ & 476 & $\mathrm{~d}_{\mathrm{mc}}(\mathrm{mm})$ & 1.713 & $\mathrm{~F}_{\mathrm{mc}}(\mathrm{N})$ & 432 \\
$\mathrm{~d}_{\mathrm{f}}(\mathrm{mm})$ & 6.806 & $\mathrm{~F}_{\mathrm{f}}(\mathrm{N})$ & 1598 & $\mathrm{~d}_{\mathrm{f}}(\mathrm{mm})$ & 8.504 & $\mathrm{~F}_{\mathrm{f}}(\mathrm{N})$ & 1401 \\
$\mathrm{~K}_{1}(\mathrm{~N} / \mathrm{mm})$ & & $536 \pm 44$ & & $\mathrm{~K}_{1}(\mathrm{~N} / \mathrm{mm})$ & & $558 \pm 49$ & \\
$\mathrm{~K}_{2}(\mathrm{~N} / \mathrm{mm})$ & & $166 \pm 16$ & & $\mathrm{~K}_{2}(\mathrm{~N} / \mathrm{mm})$ & & $103 \pm 11$ \\
$\mathrm{~K}_{3}(\mathrm{~N} / \mathrm{mm})$ & & $218 \pm 16$ & & $\mathrm{~K}_{3}(\mathrm{~N} / \mathrm{mm})$ & & $143 \pm 10$ \\
\hline
\end{tabular}

Comparing the woven 3D layup in bending (respectively $218 \mathrm{~N} / \mathrm{mm}$ and $143 \mathrm{~N} / \mathrm{mm}$ in $\mathrm{x}$ and y) with the knitted 3D layup ( $92 \mathrm{~N} / \mathrm{mm}$ in both directions) and the equivalent $2 \mathrm{D}$ layup $(72 \mathrm{~N} / \mathrm{mm})$ (Figure 14 and Table 8), showed a strong increase of the flexural post-cracking stiffness. This was in contrast with the tensile experimental results, where all the layups yielded the same post-cracking stiffness in the x-direction. Since all flexural experiments had the same anchorage length $(175 \mathrm{~mm})$ and both layups had the same flexural lever arm, as well as in-plane fiber volume fraction, this post-cracking 
stiffness increase can be attributed to the continuously woven transversal connections providing a better flexural anchorage of the in-plane textiles than their discretely knitted counterpart.

The difference in post-cracking stiffness in tension and bending between the $x$ - and y-direction of the woven 3D layup was a further suggestion towards the anchorage efficiency of these transversal connections.

Failure of the specimens happened by means of fiber pull-out, at $1598 \mathrm{~N}$ and $1401 \mathrm{~N}$ in x and $\mathrm{y}$, respectively (compared to $1503 \mathrm{~N}$ for the knitted 3D layup).

Finally, when comparing the relative failure stress and force of all layups in Figures 11 and 14, the positive influence of the transversal connections was again highlighted. The pull-out stress of the woven 3D layup in tension (respectively 4.96 MPa and 4.82 MPa along $\mathrm{x}$ and $\mathrm{y}$ ) was considerably lower than the knitted 3D and equivalent 2D layups (respectively 7.02 MPa and 7.52 MPa). In bending, however, the average pull-out force of the woven 3D layup (respectively $1598 \mathrm{~N}$ and $1401 \mathrm{~N}$ ) was similar or even higher than the knitted 3D and equivalent 2D layups (respectively $1503 \mathrm{~N}$ and $1456 \mathrm{~N}$ ). This shows that in the loading condition where the transversal connections were activated, the woven $3 \mathrm{D}$ transversal connections achieved a superior anchorage of the in-plane textiles than their knitted 3D counterpart.

A hypothesis for the activation of the transversal connections in bending and not in tension can be linked to the different loading conditions of the individual textile layers in both alternatives. In tension, both the top and the bottom textile layer were subjected to equal tensile forces, while in bending the top layer was subjected to compression and the bottom layer to tension. At the level of the transversal connections, this translates to a zero stress-value gradient over their length (in the composite's thickness direction) in tension and a constant stress gradient in bending. This stress gradient is believed to activate their anchoring effects, leading to the observed mechanical improvement in bending rather than tension.

\section{Conclusions}

This paper investigated the influence of the loading direction (with respect to the orientation of the transversal connections) on the mechanical response of both a knitted 3D and woven TRC layup. In tension, no influence of the transversal connections on the post-cracking stiffness was reported, independently of the type of connections or orientation. These observations showed the independence of the tensile mechanical behavior of TRCs to the presence of transversal connections. The woven 3D TRCs did, however, show a lower post-cracking stiffness and a higher failure strain in the warp (y-) direction due to the waviness of the yarns. In bending, all 3D TRC configurations and loading directions showed a significant increase of the post-cracking stiffness compared to the reference equivalent 2D layup. These results clearly highlighted the flexural anchorage mechanism provided by the transversal connections, with increases up to three times the post-cracking stiffness (for the 3D woven layup along $\mathrm{x}$ ).

The knitted 3D TRC layup showed a post-cracking stiffness increase of $25 \%$ regardless of the orientation of the transversal connections, while the woven 3D TRC exhibited a stiffer behavior in the weft ( $\mathrm{x}$-) direction. This corresponds to the stiffer tensile behavior in pure tension in the plane of the straightened longitudinal fibers, but is perpendicular to the plane in which the connections are woven with the in-plane textiles. These results indicate that a woven $3 \mathrm{D}$ textile remains more effective in the weft direction, despite the transversal connections being oriented in the perpendicular plane (warp direction). Nonetheless, the transversal fibers contribute to such an extent to the loadbearing behavior of the TRC that the 3D textiles in the warp direction outperform the 3D knitted layups in bending, while in tension they were clearly inferior. This illustrates the significant difference in anchorage that can be achieved when using different types of connections.

These results highlighted the potential of 3D TRCs when used in structural applications, not only for the manufacturing ease but also for the mechanical response, especially when considering that the transversal connections of both layups were made of polyester, a non-structural material. 
However, when aiming towards future design, a thorough knowledge of the loading conditions in which the transversal connections are activated is required. Therefore, future work should investigate the activation of transversal connections for larger structural elements, such as bi- or multi-directionally loaded plates.

Author Contributions: Conceptualization, M.E.K. and T.T.; Data curation, M.E.K.; Funding acquisition, D.V.H.; Resources, P.K.; Supervision, T.T.; Writing—original draft, M.E.K.; Writing—review \& editing, J.W. and T.T. All authors have read and agreed to the published version of the manuscript.

Funding: This research was funded by Fonds Wetenschappelijk Onderzoek (FWO), grant number IWT697.

Acknowledgments: This research was made possible thanks to the materials provided by our research partner "3D Weaving" within the larger SBO-project "CecomStruct" funded by the "Agentschap Innoveren \& Ondernemen" as well as the experimental campaigns performed within the Interreg project "Beton naar hoogwaardig beton".

Conflicts of Interest: The authors declare no conflict of interest.

\section{References}

1. Brameshuber, W. Textile Reinforced Concrete: State of the Art Report. RILEM Technical Committee 201-TRC, 1st ed.; RILEM Publications: Aachen, Germany, 2006.

2. Bentur, A.; Mindess, S. Fibre Reinforced Cementitious Composites; Taylor and Francis: New York, NY, USA, 2007; 601p.

3. Aveston, J.; Cooper, G.A.; Kelly, A. Single and Multiple Fracture. In Proceedings of the Properties of Fibre Composites, London, UK, November 1971.

4. Hegger, J.; Kulas, C.; Horstmann, M. Spatial Textile Reinforcement Structures for Ventilated and Sandwich Facade Elements. Adv. Struct. Eng. 2016, 15, 665-675. [CrossRef]

5. Triantafillou, T.; Papanicolaou, C.G. Shear Strengthening of Reinforced Concrete Members with Textile Reinforced Mortar (TRM) Jackets. Mater. Struct. 2006, 39, 93-103. [CrossRef]

6. Brückner, A.; Ortlepp, R.; Curbach, M. Anchoring of Shear Strengthening for T-Beams Made of Textile Reinforced Concrete (TRC). Mater. Struct. 2008, 41, 407-418. [CrossRef]

7. Contamine, R.; Si Larbi, A.; Hamelin, P. Identifying the Contributing Mechanisms of Textile Reinforced Concrete (TRC) in the Case of Shear Repairing Damaged and Reinforced Concrete Beams. Eng. Struct. 2013, 46, 447-458. [CrossRef]

8. Si Larbi, A.; Agbossou, A.; Hamelin, P. Experimental and Numerical Investigations about Textile-Reinforced Concrete and Hybrid Solutions for Repairing And/or Strengthening Reinforced Concrete Beams. Compos. Struct. 2013, 99, 152-162. [CrossRef]

9. Verbruggen, S.; Remy, O.; Wastiels, J.; Tysmans, T. Stay-in-Place Formwork of TRC Designed as Shear Reinforcement for Concrete Beams. Adv. Mater. Sci. Eng. 2013, 2013, 1-9. [CrossRef]

10. Peled, A.; Bentur, A.; Mobasher, B. Textile Reinforced Concrete; Taylor and Francis: New York, NY, USA, 2017.

11. Hegger, J.; Horstmann, M.; Zell, M. Applications for TRC. In Proceedings of the 15th International Congress of the International Glassfibre Reinforced Concrete Association (GRCA), Prague, Czech Republic, April 2008.

12. Tysmans, T.; Adriaenssens, S.; Cuypers, H.; Wastiels, J. Structural Analysis of Small Span Textile Reinforced Concrete Shells with Double Curvature. Compos. Sci. Technol. 2009, 69, 1790-1796. [CrossRef]

13. Scholzen, A.; Chudoba, R.; Hegger, J. Thin-walled shell structures made of textile-reinforced concrete Part I: Structural design and construction. Struct. Concr. 2015, 16, 106-114. [CrossRef]

14. Verwimp, E.; Tysmans, T.; Mollaert, M.; Berg, S. Experimental and numerical buckling analysis of a thin TRC dome. Thin-Walled Struct. 2015, 94, 89-97. [CrossRef]

15. Cuypers, H.; Wastiels, J. Analysis and Verification of the Performance of Sandwich Panels with Textile Reinforced Concrete Faces. J. Sandw. Struct. Mater. 2011, 13, 589-603. [CrossRef]

16. Vervloet, J.; Tysmans, T.; El Kadi, M.; De Munck, M.; Panagiotis, P.; Van Itterbeek, P.; Wastiels, J.; Van Hemelrijck, D. Validation of a Numerical Bending Model for Sandwich Beams with Textile-Reinforced Cement Faces by Means of Digital Image Correlation. Appl. Sci. 2019, 9, 1253. [CrossRef]

17. Helbig, T.; Rempel, S.; Unterer, K.; Kulas, C.; Hegger, J. Fuß- und Radwegbrücke aus Carbonbeton in Albstadt-Ebingen. Die weltweit erste ausschließlich carbonfaserbewehrte Betonbrücke. Beton-und Stahlbetonbau 2016, 111, 676-685. [CrossRef] 
18. Elsanadedy, H.M.; Almusallam, T.H.; Alsayed, S.H.; Al-Salloum, Y.A. Flexural strengthening of RC beams using textile reinforced mortar - Experimental and numerical study. Compos. Struct. 2013, 97, 40-55. [CrossRef]

19. Zhu, D.; Mobasher, B.; Peled, A. Experimental study of dynamic behavior of cement-based composites. Constr. Build. Mater. 2011, 2, 1-12. [CrossRef]

20. Amzaleg, E.; Peled, A.; Janetzko, S.; Gries, T. Flexural Behaviour of Cement Based Element Reinforced with 3D Fabric. In Proceedings of the VIII International Conference on Fracture Mechanics of Concrete and Concrete Structures, Toledo, Spain, 11 March 2013.

21. El Kadi, M.; Tysmans, T.; Verbruggen, S.; Vervloet, J.; De Munck, M.; Wastiels, J.; Van Hemelrijck, D. Experimental study and benchmarking of 3D textile reinforced cement composites. Cem. Concr. Compos. 2019, 104, 1-10. [CrossRef]

22. Peled, A.; Haik, R.; Sasi, E.A. Influence of three-dimensional (3D) fabric orientation on flexural properties of cement-based composites. Cem. Concr. Compos. 2017, 80, 1-9.

23. Dvorkin, D.; Poursaee, A.; Peled, A.; Weiss, W.J. Influence of bundle coating on the tensile behavior, bonding, cracking and fluid transport of fabric cementbased composites. Cem. Concr. Compos. 2013, 42, 9-19. [CrossRef]

24. Donnini, J.; Corinaldesi, V.; Nanni, A. Mechanical properties of FRCM using carbon fabrics with different coating treatments. Compos. Part B Eng. 2016, 88, 220-228. [CrossRef]

25. Signorini, C.; Nobili, A.; Sola, A.; Messori, M. Designing epoxy viscosity for optimal mechanical performance of coated Glass Textile Reinforced Mortar (GTRM) composites. Constr. Build. Mater. 2020, 233, 1-12. [CrossRef]

26. El Kadi, M.; Tysmans, T.; Verbruggen, S.; Wastiels, J.; Vervloet, J.; De Munck, M.; Van Hemelrijck, D. A layered-wise, composite modelling approach for fibre textile reinforced cementitious composites. Cem. Concr. Compos. 2018, 94, 107-115. [CrossRef]

27. Sika. Sikagrout 217, Note de Produit. Available online: https://www.sika.com/ (accessed on 28 June 2020).

28. Fraas, V. Technical Datasheet SitGrid701. Available online: https://www.solutions-in-textile.com (accessed on 28 June 2020).

29. Ghekiere, P. 3D Weaving, Strong in Development. Available online: https://www.3dweaving.com (accessed on 28 June 2020).

30. Fraas, V. Technical Datasheet SitGrid200. Available online: https://www.solutions-in-textile.com (accessed on 28 June 2020).

31. Brameshuber, W. Uniaxial Tensile Test: Test Methods and Design of Textile Reinforced Concrete. Mater. Struct./Mater. et Constr. 2016, 49, 4923-4927.

32. Sutton, M.A.; Orteu, J.-J.; Schreier, H.W. Image Correlation for Shape, Motion and Deformation Measurements; Springer Science + Business Media: New York, NY, USA, 2009. 